\title{
Explore the Design Style of Oriented Facility Based on User Evaluation
}

\author{
Ye Zhang ${ }^{1,2}$ Yang Liu ${ }^{1}$ \\ ${ }^{1}$ School of Architecture and Art Design, \\ Beijing Jiaotong University, \\ Beijing 100044, China \\ 531892226@qq.com
}

\author{
Hui $\mathrm{Yu}^{2}$ \\ ${ }^{2}$ School of Creative Technologies, \\ University of Portsmouth \\ Portsmouth PO1 2DJ, United Kingdom \\ hui.yu@port.ac.uk
}

\begin{abstract}
This paper employs Kansei engineering to analyze the relationship between user preference and the given architectural design scheme. In this study, we first divide architectural styles into seven different categories. Then we classify the key factors in the oriented facility design into 7 types with 39 subcategories. On that basis, we explore which design factor plays main roles in the harmony and unity between the user-oriented type and the given architectural design among seven different architectural styles (the national refined style). And then the SD method is used to compare the architectural style sample to the oriented facilities samples in order to obtain the data of matching degree between them. Through analyzing the collected data, we put forward the design model based on design factors of guild facility model, which is adapted to the particular architecture styles.
\end{abstract}

Keywords-Architectural image; Orientated facility; Image relevance; Certain algorithm; Kansei engineering

\section{INTRODUCTION}

Oriented facility plays a constituent part of largescale public building. The single style needs to be coordinated and related to the architectural spatial form, which is the significant factor that contributes to a successful design. In the process of large-scale architecture design, once the architectural design scheme has been settled, the model design of oriented system can carry out accordingly. In this phase, the most valuable material for designers is the effect images. With the premise of reaching the effects of harmony between architectural style and oriented facility model scheme, several questions are aroused: how can we get general consent by architectural users in the future, and which factor is essential to make oriented facility matched with architectural style. Can we establish an Intelligent Identification Systems to reach the purpose: when we input a certain architectural image and the system is able to analyze the feature of architectural image via image identification and definite classification, the systems can provide a number of oriented design reference images coordinating and unifying certain architecture? This subject is definitely of great values in the designing work.

The large-scale public building can be classified into various types, such as rail transport hub, museums, commercial complexes and administrative office centers, etc. Large-scale rail transit station buildings serve as our first research objectives. In last decade, Chinese high-speed rail developed rapidly. A number of medium-large cities built their own newstyle high-speed rail stations in large scale. In China, it is one of the hottest fields for investment. These comprehensive public transport hub spaces also serve as the epitome of the tendency of current Chinese large-scale public buildings style. Owing to the large number of such new rail station, their functions are such similar. We probably evaluate the most representative station images among large-scale hub architectures, and divide them into five levels according to time dimension of the design style. In this paper, we perform an evaluation on how certain level of the station architectural styles influenced the user's preference on corresponding oriented facilities models. In this study, we will work out a relationship between the building style and oriented design features. This will provide the mature route for the definition of the relevance between other type of architecture design and corresponding oriented design.

After fixing the research objective buildings, the first thing that needs to be clear is to define the best matching architectural style for the oriented facility. We need to establish a known orientation facilities modeling image sample library, and simplify certain number of representative samples for user research. Then we display representative samples and target building images side by side, using Kansei Engineering 


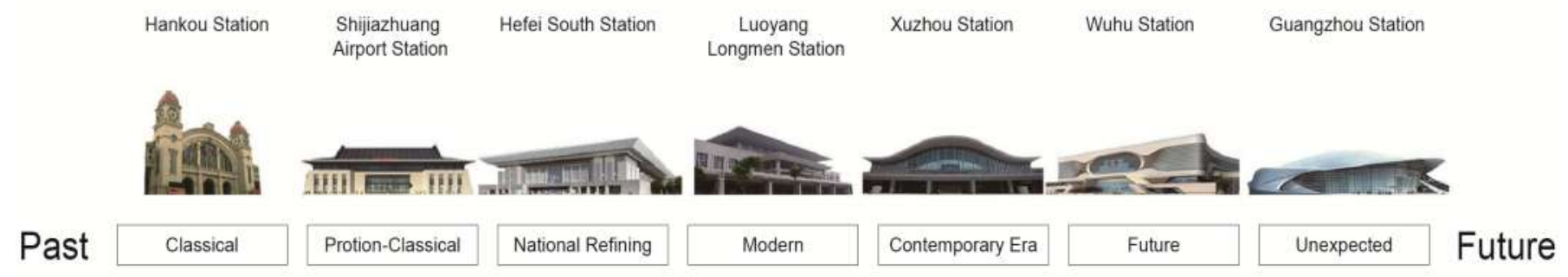

Fig. 1. The 7 styles of rail station building

semantic differences(SD)method [1] test user the monomer modeling-target-oriented facilities architectural image of the harmonizing taste to see in the eyes of the masses of people that non-professional designers, which oriented facilities form is considered to be the most suitable for the target architecture.

Then the question is even more critical. That is which linguistic elements (design element) determine the harmonious unification of the oriented facility modeling and the target architectural forms. Modeling styles are determined by the design form language, such as symmetry, square, visual stable form and so on. We further subdivided the linguistic constitutional design elements of oriented monomer model by the virtue of design professionals' classification. Furthermore, we made one-one comparison between constitutional elements of design which represent image sample and orientated facilities' model to establish linguistic database. Combining with the result of SD testing, we made it clear of which design elements are key factor to oriented facilities matching with the architectural style under the conditions of the given target architecture style by using of certain algorithm.

\section{USER TESTING}

User's psychological expectation to the product has a close relationship with design process form and product style design [2]. As an ergonomic user-centered methodology, Kansei Engineering has been successfully applied in exploring the relationship between psychological feelings of users and the design elements of the system or system [3-7]. By the most suitable adjective pairs, the Intention multidimensional method was used to do quantitative research and statistics on users' psychological preference, combining with the image of the design results [8]. In this paper, we organize a Kansei Engineering consumer-oriented experiment to define oriented facility's model and particular type of architectural images. The experiment divides the volunteers into three groups. Group-A consists of seven males and eight females. The average age of the group members is 25 . These young people have non-design educational background. Meanwhile they have more than sixyear-experience in Web search and Information Retrieval. They are mainly responsible for collecting the image information of the goal-oriented architectures and oriented facilities. Their non-professional backgrounds can make the collection of materials and images without any tendency in style. The Group-B composes of five design experts. Three males and two females, the average age is 32 . Each of them has at least six years of oriented facility design experience. They are clearly aware of the constitutional elements of oriented design. They can define the key oriented facility modeling by professional discussion and finally the representative fix images of user testing. Group-C has 32 participants (21 males and 11 females whose the average age are 36). They are very close to the average age of the public transportation building space's users).

\section{A. Determining given architectural image sample}

Fifteen young people in Group-A research group collect 100 images of representative railway station building in the scope of China from magazines, websites and books, which covers main high-speed rail station building effect images of the newly-build provincial capitals and regional center city. It also contains some very old but important classical rail station images with ethnic characteristics.

We use seven scales (1-7) of the semantic differential method to divide various types of rail stations in order to definite a better classification dimensions. We just put one classified dimension into consideration: the reflected architectural style inclines to the past (traditional sense), or tends to be future (more novelty). Take this as standard, we divided buildings into the seven types: completely classical, portioned classical, national refined, modern, contemporary, future, and unimagined. The seven architectural types gradually transits from the past to the future. Figure 1 shows these seven types, each of which is considered one of the most representative buildings of this type.

\section{Prepare Your Paper Before Styling}

We asked the five design experts of Group-B to form a focus group and generalize 100 images. Based on the similarity and time sequence of image's style shown in Figure 1, they filled images to seven different style image stocks. Afterwards, the design experts discuss together to select six representative images from each type, according to the most representative principle. The "national refined" style type is used for this textual research which has been widely used in Chinese largescale high-speed rail station design in recent years. The purpose of architectural designers is to satisfy the operating functions as modern newly-build high -speed rail hub, and at meantime illuminate local historical culture. We study the relevance of such architecture style and its facilities, with the most urgent and extensive value. Group-B then extracts the six most representative of the station building image from 


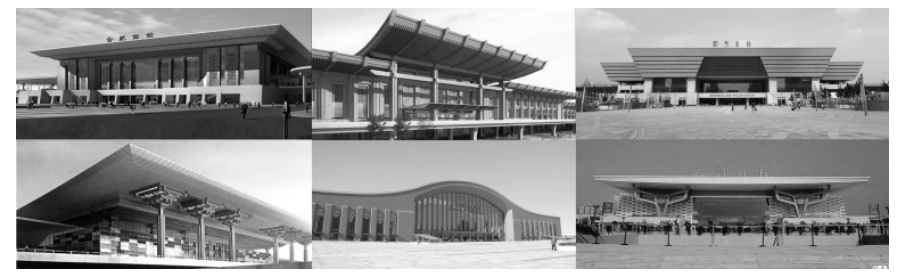

Fig. 2. The six representative images of national refining architecture style Example of a figure caption. (figure caption)
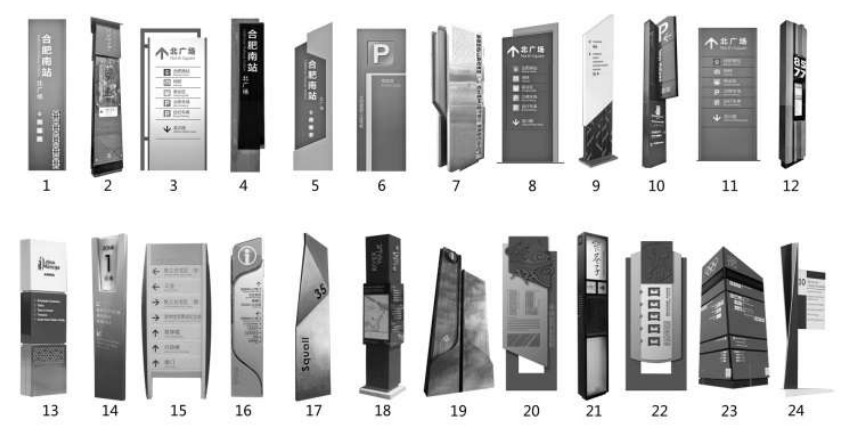

Fig. 3. The 24 representative oriented facilities samples.

"national extraction" image stores as the target architecture image for SD testing (Fig.2).

\section{B. Determining oriented facilities images sample}

We use the Kawakida Jirou method [10] to the determine the test images, which was proposed by Kawakida Jirou 1953 to sort out typical ideas, concepts, objects, and other things according to their similarity [11]. Research Group-A has collected more than 200 identity-oriented images from network, magazines, books and other channels.

Some steps are taken to make the data more concise for identity-oriented facility analysis. The first step is to merge or delete the similar image in form and style. They select 24 identity-oriented facilities which are nearest to the refined style in their mind by their rich experience. The second step is to mark the number for the images, and get the modeling information of oriented facilities which is use for text methods of the Kansei Engineering.

\section{Morphological analysis of Oriented Design' Modeling factors $x$ after your paper is styled}

Group-B, consisting of five expert designers, carried out the morphological analysis in order to mark off the major factors of oriented facilities. Firstly, they are asked to write down the key design elements of oriented facilities according their own experiences and knowledge. And then they opened up a focus group discussion and supplement some missing forms by means of observing 200 oriented facilities images. Finally, they combined the same ideas and elements, and delete some unimportant or similar forms, which ensure each design form is critical with independent feature. The result of discussion is shown in Table 1 . It is easily seen that there are seven mainly forms which determine oriented facilities' form, including style, repeat, outline, partial relationship, hollow, top shape, and body shape. These seven main forms can be subdivided
TABLE I. MORPHOLOGICAL ANALYSIS ON THE 24 REPRESENTATIVE ORIENTED FACILITIES SAMPLES

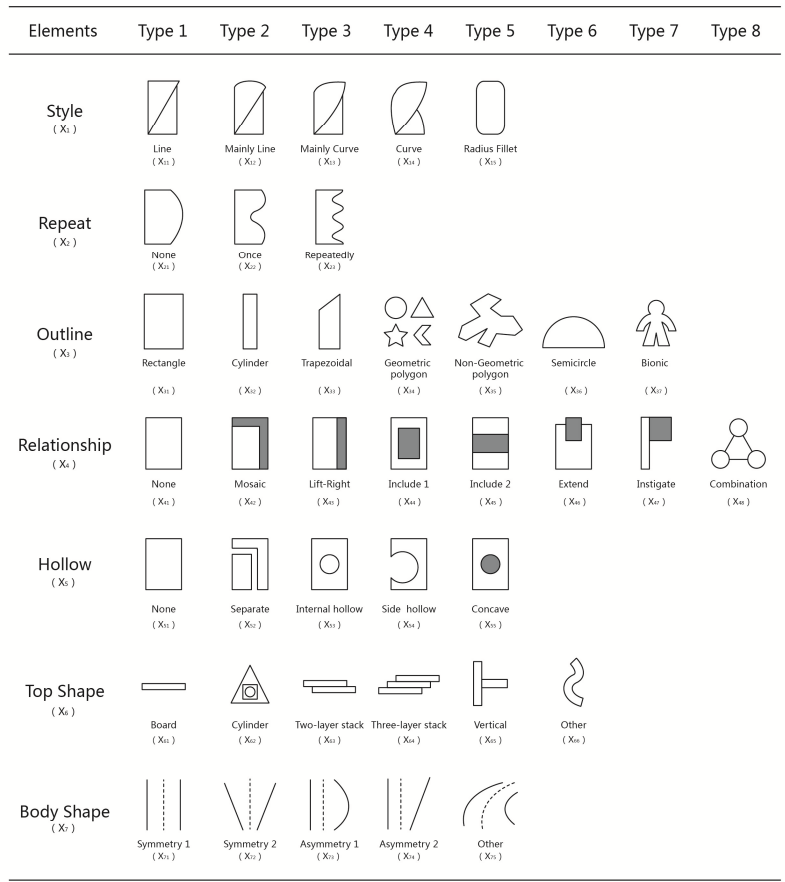

into 39 smaller forms. Thus we have built up a landing-type forms elements database of oriented facilities which will be useful for further research.

\section{Kansei Engineering Method Of SD Test}

In Kansei engineering, intention scale method is frequently used to take quantitative test for users' psychology. In this paper, there are two sets of given images (6 pieces of architecture images and 24 pieces of oriented facilities images). The process is to ask the participants to make a judgment on each oriented facility image, whether its style, design modeling, favor is in harmony with architecture, and whether it has relevance in design. The participants their feelings using adjective: unfit for 1 point, fit for 5 points. According to the 5 levels of SD method, psychological feelings are divided into 5 different levels. When the participants meet a certain number, we can get an average of psychological quantitative values. In order to better describe the users' feeling about the linkages between building (the target image) and oriented modeling (tests images), we need to test following issues

1) To determine the most suitable adjective pairs

a) We hope all the participants understand the target of text, in order that they can assess whether the oriented facility is in harmonious with the given image, after evaluating the given photo of architecture, and observing one by one. It can conclude whether it can exist as good architecture orientated form. Therefore we selected over 30 adjectives which convey opponent sense of meaning, such as fit and unfit, adapt to the environment - do not adapt to the environment, contrast - coordination and so on. By semantic differential method analysis, we finally determine suitable-unsuitable ( $F$ - 
$U)$ are the most suitable for this test, and put these adjectives as the key word of this test.

2) We finally used SD method to make comparison between 24 orientated facilities in Figure 3 with architectural images in Table 2 one by one to assess their harmonious degree of correlation from consumer's aesthetic angle. In order to guarantee the subject of the test is only focusing on the modeling problem, we use the non color gray-scale images. Firstly, let 32 participants of the third group observe the building images (Table 1), and form the overall impression of the building. Then by five different levels of psychological variables, we made a judgment on the former and the latter's $F-U$ degree. Table 2 shows the final result. The counts of the first column display each oriented facility number; the 2nd 10th column show the language element form corresponding to 24 oriented facilities after analysis of experts group. These design elements come from Table 1, which represent corresponding relationship between oriented facilities and the design elements. Last 4 columns of table 2 shows 24-oriented facilities test data, including average, standard deviation, maximum and minimum scores. Highest average is 8th oriented facility, which is 3.81, 10th the second highest with its number 3.78. No. 15-oriented facility have the lowest value which is 2.72. The next step we can future explore the constitutional design factors which is recognized by user's preference through Table 2 's database.

TABLE II. NUMERICAL DATA SOURCE FOR THE 24 REPRESENTATIVE ORIENTED FACILITIES SAMPLES

\begin{tabular}{|l|l|l|l|l|l|l|l|l|l|l|l|l|}
\hline $\mathbf{N}$ & $\mathbf{X}$ & $\mathbf{X}$ & $\mathbf{X}$ & $\mathbf{X}$ & $\mathbf{X}$ & $\mathbf{X}$ & $\mathbf{X}$ & & $\mathbf{F}-\mathbf{U}$ & & & \\
$\mathbf{0 .}$ & $\mathbf{1}$ & $\mathbf{2}$ & $\mathbf{3}$ & $\mathbf{4}$ & $\mathbf{5}$ & $\mathbf{6}$ & $\mathbf{7}$ & & value & & & \\
\hline & & & & & & & & & Average & $\begin{array}{c}\boldsymbol{M i} \\
\boldsymbol{n}\end{array}$ & $\begin{array}{c}\boldsymbol{M} \\
\boldsymbol{a x}\end{array}$ & $\begin{array}{l}\text { Standard } \\
\text { deviation }\end{array}$ \\
\hline $\mathbf{1}$ & 1 & 1 & 1 & 1 & 3 & 1 & 1 & & 3.44 & 1 & 5 & 0.98 \\
\hline $\mathbf{2}$ & 1 & 1 & 2 & 5 & 1 & 3 & 2 & & 2.97 & 1 & 5 & 1.12 \\
\hline $\mathbf{3}$ & 1 & 1 & 1 & 2 & 2 & 1 & 1 & & 3.75 & 2 & 5 & 0.92 \\
\hline $\mathbf{4}$ & 1 & 1 & 2 & 6 & 1 & 3 & 1 & & 3.50 & 2 & 5 & 0.92 \\
\hline $\mathbf{5}$ & 1 & 1 & 3 & 2 & 5 & 3 & 1 & & 3.25 & 1 & 5 & 0.95 \\
\hline $\mathbf{6}$ & 1 & 1 & 1 & 2 & 5 & 3 & 1 & & 2.84 & 1 & 5 & 0.95 \\
\hline $\mathbf{7}$ & 1 & 1 & 1 & 3 & 1 & 3 & 3 & & 3.13 & 1 & 5 & 1.21 \\
\hline $\mathbf{8}$ & 1 & 1 & 3 & 2 & 1 & 3 & 1 & & 3.81 & 2 & 5 & 0.93 \\
\hline $\mathbf{9}$ & 1 & 1 & 3 & 5 & 5 & 3 & 1 & & 3.19 & 1 & 5 & 1.15 \\
\hline $\mathbf{1 0}$ & 1 & 1 & 2 & 7 & 1 & 5 & 3 & & 3.78 & 2 & 5 & 1.10 \\
\hline $\mathbf{1 1}$ & 1 & 1 & 1 & 1 & 1 & 1 & 1 & & 3.25 & 1 & 5 & 1.08 \\
\hline $\mathbf{1 2}$ & 1 & 1 & 2 & 5 & 1 & 4 & 1 & & 3.34 & 1 & 5 & 1.15 \\
\hline $\mathbf{1 3}$ & 1 & 3 & 1 & 5 & 1 & 2 & 1 & & 3.53 & 1 & 5 & 1.16 \\
\hline $\mathbf{1 4}$ & 2 & 1 & 2 & 5 & 4 & 3 & 2 & & 3.38 & 1 & 5 & 1.04 \\
\hline $\mathbf{1 5}$ & 3 & 1 & 1 & 1 & 4 & 1 & 1 & & 2.72 & 1 & 4 & 0.99 \\
\hline $\mathbf{1 6}$ & 5 & 2 & 3 & 5 & 1 & 1 & 1 & & 3.53 & 1 & 5 & 1.08 \\
\hline $\mathbf{1 7}$ & 1 & 2 & 5 & 5 & 1 & 1 & 3 & & 2.97 & 1 & 5 & 1.26 \\
\hline $\mathbf{1 8}$ & 1 & 1 & 2 & 5 & 1 & 2 & 1 & & 3.41 & 1 & 5 & 1.21 \\
\hline $\mathbf{1 9}$ & 2 & 2 & 5 & 5 & 5 & 3 & 3 & & 3.56 & 1 & 5 & 1.27 \\
\hline $\mathbf{2 0}$ & 1 & 2 & 1 & 6 & 3 & 4 & 3 & & 3.75 & 1 & 5 & 1.30 \\
\hline $\mathbf{2 1}$ & 1 & 1 & 2 & 5 & 5 & 2 & 1 & & 3.16 & 1 & 5 & 1.05 \\
\hline $\mathbf{2 2}$ & 2 & 1 & 1 & 6 & 3 & 4 & 1 & & 3.38 & 1 & 5 & 1.18 \\
\hline $\mathbf{2 3}$ & 1 & 3 & 3 & 5 & 1 & 2 & 4 & & 3.41 & 1 & 5 & 1.27 \\
\hline $\mathbf{2 4}$ & 3 & 1 & 5 & 7 & 5 & 5 & 5 & & 3.47 & 2 & 5 & 1.02 \\
\hline & & & & & & & & & \\
\hline
\end{tabular}

\section{ANALYSIS}

We compute the correlation coefficient of the 39 substyles and ratings of the subjects using the following equation:

$$
r_{x y}=\frac{n \sum_{i=1}^{n} x_{i} y_{i}-\sum_{i=1}^{n} x_{i} \sum_{i=1}^{n} y_{i}}{\sqrt{n \sum_{i=1}^{n} x_{i}^{2}-\left(\sum_{i=1}^{n} x_{i}\right)^{2}} \sqrt{n \sum_{i=1}^{n} y_{i}^{2}-\left(\sum_{i=1}^{n} y_{i}\right)^{2}}}
$$

The proportion of the 39 styles was taken where the correlation was statistically significant at the significance level $p<0.05$. Fig. 4 (a) shows the number of rating with statistical significance of all the 5 levels of rating for all the 39 styles. The $\mathrm{x}$-axis represents the 39 subcategories of the design style and the y-axis is the significance rating number. Fig. 4 (b) demonstrates the statistical significance rating number of the $5^{\text {th }}$ level rating only. As we can see from figure (b), there are total 21 subcategories are rated as the significant design styles. Among these, there are 9 subcategories are rated above 3, which are taken as the most related design styles based on the 24 given images.

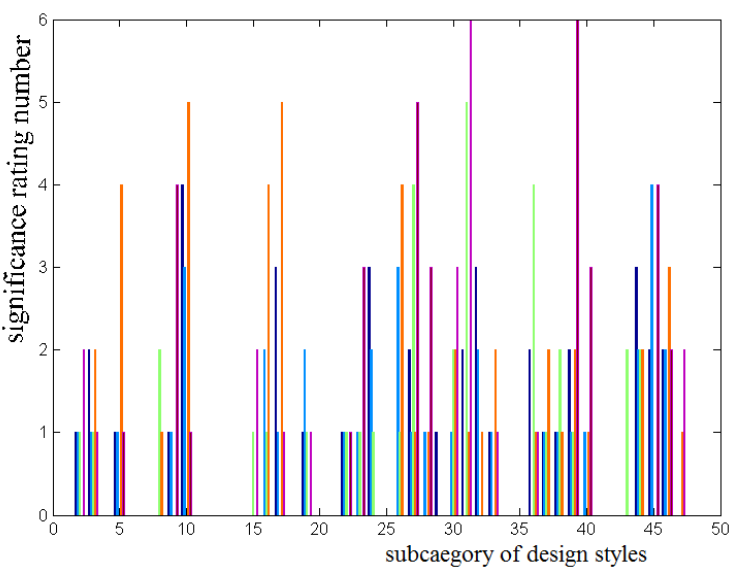

(a)

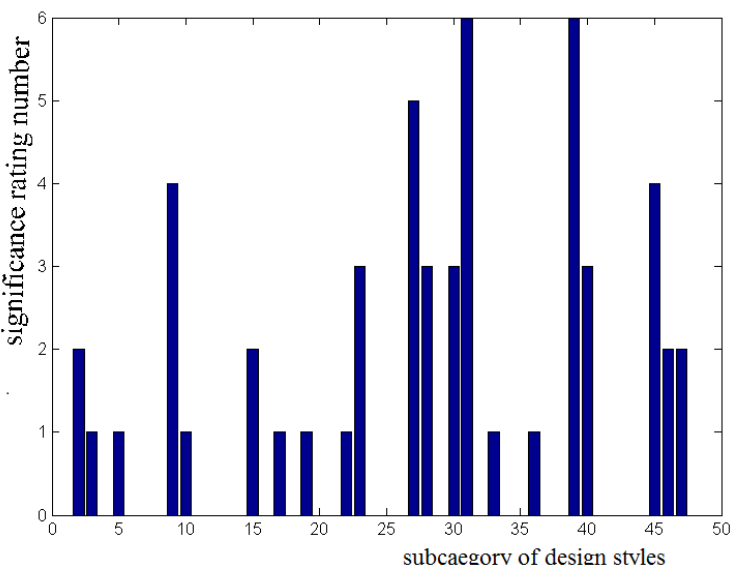

(b)

Fig. 4 Statistically significant design styles 


\section{CONCLUSION}

Based on the classification of the seven different architectural styles, the paper selected a large-scale public transport as the studying case and discussed which design factors played main roles in the harmony and unity between the oriented facilities form and the given architecture images. By means of the Kansei engineering tests, we took fit or not fit as the evaluation index of the tests to get the preference data of the users. Then we further use certain algorithm to analyze and put forward the detail compositions and elements of the oriented facility design which are needed to be focus on during the design process. Furthermore, we proposed a certain model so as to solve the resources problems of refined style design elements during the process of oriented facility design of largescale public transport architecture. In the future, based on the analytical method above, we can build up the comprehensive database of the oriented facility system which is in accordance to the total 7 different architectural styles. This is expected to provide optimum scheme proposals to the oriented facility designers. The next destination of research is that: the algorithm will be put forward. Once the architecture image is provided, the algorithm will provide the detailed architecture style automatically. This algorithm help to realize a pattern, which is the process of image input - automatic matching system - output the detailed guidance facility type - the reference image. Meanwhile, this automatic algorithm can greatly help facilitating the designers, especially for the ACBJ who is in response of the work distribution.

\section{ACKNOWLEDGMENT}

This project was supported by "the Fundamental Research Funds for the Central Universities" (2014JBW001, Beijing Jiaotong University, China). The authors also thank the 40 subjects in china for their participation and assistance in the experimental study.
[1] Osgood. C.E., Suci. C.J, The Measurement of Meaning. University of Illinois Press, Urbana, 1957.

[2] Hsiao, S.-W., Tsai, H.-C, 2005. Applying a hybrid approach based on fuzzy neural network and genetic algorithm to product form design.International Journal of Industrial Ergonomics 35, pp. 411-428.

[3] Ishihara. S, Ishihara. K, Nagamachi. M, An automatic builder for a kansei engineering expert system using self-organizing neural networks. International Journal of Industrial Ergonomics 15, 1995, pp. 2537.

[4] Lin, Y-C, Lai, H-H, Yeh C-H, Consumer-oriented product form design based on fuzzy logic: a case study of mobile phones. International Journal of Industrial Ergonomics 37, 2007, 531-543.

[5] Schutte. S, Eklund. J, Design of rocker switches for work-vehicles-an application of Kansei Engineering. Applied Ergonomics 36, 2005, 557567.

[6] Zhai L-Y, Khoo L-P, Zhong Z-W, A rough set based decision support approach to improving consumer affective satisfaction in product design. International Journal of Industrial Ergonomics 39, 1995, pp. 295-302.

[7] Yang-Cheng Lin, Chung-Hsing Yeh, Chun-Chun Wei, How will the use of graphics affect visual aesthetics? A user-centered approach for web page design. International Journal of Human-Computer Studies 71, 2013, pp. 217-227.

[8] Nagamachi. M, Kansei Engineering: a new ergonomics consumeroriented technology for product development. International Journal of Industrial Ergonomics 15, 1995, pp. 3-11.

[9] Nielsen. J, Usability Engineering. Academic Press, United Kingdom, 1993.

[10] Cross. M, Engineering Design Methods. Wiley, London, 1994.

[11] Yan-Cheng Lin, Hsin-His Lai, Chung-Hsing Yeh, Consumer-oriented product form design based on fuzzy logic:Acase study of mobile phones. International Journal of Industrial Ergonomics 37, 2007, pp. 531-543.

\section{REFERENCES}

